\title{
The impact of sequential versus single anastomoses on flow characteristics and mid-term patency of saphenous vein grafts in coronary bypass grafting
}

\author{
Hee Jung Kim, MD, Taek Yeon Lee, MD, Joon Bum Kim, MD, Won Chul Cho, MD, Sung Ho Jung, MD, \\ Cheol Hyun Chung, MD, Jae Won Lee, MD, and Suk Jung Choo, MD
}

\begin{abstract}
Objective: To assess the influence of bypass grafting technique on the flow characteristics and mid-term patency of saphenous vein coronary bypass grafts.
\end{abstract}

\begin{abstract}
Methods: In the present study, 309 patients who underwent either sequential (group A, N = 84 grafts) or individual (group B, $N=244$ grafts) saphenous vein coronary bypass grafting between February 2002 and September 2007 were investigated. Individual bypassing only was performed in 212 patients, and sequential bypassing only was performed in 78 patients. The remaining 19 patients received both. A total of 436 distal anastomoses were performed with 328 saphenous vein grafts. The intraoperative flow characteristics and the graft patency were assessed with the transit time flow meter and serial multi-detector computed tomography coronary angiograms, respectively.
\end{abstract}

Results: Group A showed a higher mean flow compared with group B at $49.4 \pm 27.4 \mathrm{~mL} / \mathrm{min}$ versus $37.1 \pm 20.1$ $\mathrm{mL} / \mathrm{min}$, respectively $(P=.001)$. The mean flow increased linearly as the number of anastomoses increased per graft $(P<.001)$. Graft patency at 3 years was $93.3 \% \pm 3.4 \%$ in group $\mathrm{A}$ and $86.5 \% \pm 3.1 \%$ in group B $(P=.048)$. After adjustment for baseline characteristics, group A showed a tendency for superior mid-term patency than group B (hazard ratio $0.362 ; 95 \%$ confidence interval, $0.129-1.017 ; P=.0538$ ).

Conclusions: Sequential bypass grafts were associated with higher mean flows and superior mid-term patency compared with individual grafts. These findings suggest the more favorable results of sequential bypass grafting to be attributed to the enhanced flow hemodynamics. (J Thorac Cardiovasc Surg 2011;141:750-4)

To date, the evidence to suggest an optimal coronary bypass grafting strategy with the saphenous vein (SV) graft is unresolved. One reason lies in the lack of sufficient clinical data to adequately support a correlation between the bypass grafting technique with both the hemodynamic flow characteristics and long-term patency. Several studies have indicated the patency of sequential SV coronary bypass grafts to be superior to individual bypass grafts. ${ }^{1-6}$ However, concerns regarding the potential risk of a high proximal occlusion causing major myocardial ischemic events have discouraged many surgeons from more actively using this technique. The present study was conducted to investigate the relationship between the coronary bypass grafting technique and both the hemodynamic flow characteristics

From the Department of Cardiovascular Surgery, Asan Medical Center, College of Medicine, University of Ulsan, Seoul, Korea.

This study was supported by the Education and Research Fund 2008-459 of Asan Institute for Life Sciences, Seoul, Korea.

Disclosures: Authors have nothing to disclose with regard to commercial support.

Drs H. J. Kim and T. Y. Lee contributed equally as first authors.

Received for publication Nov 5, 2009; revisions received April 6, 2010; accepted for publication May 20, 2010; available ahead of print July 2, 2010.

Address for reprints: Suk Jung Choo, MD, Department of Cardiovascular Surgery, Asan Medical Center, University of Ulsan, College of Medicine, 388-1 Poongnap2-dong, Songpa-gu, Seoul 138-736, South Korea (E-mail: sjchoo@ amc.seoul.kr).

$0022-5223 / \$ 36.00$

Copyright (c) 2011 by The American Association for Thoracic Surgery doi:10.1016/j.jtcvs.2010.05.037 and mid-term patency of SV grafts using transit time flow measurement (TTFM) and multi-detector computed tomography (MDCT) coronary angiogram.

\section{MATERIALS AND METHODS \\ Patients}

Of the 1424 patients who underwent coronary artery bypass surgery at Asan Medical Center between February 2002 and September 2007, 458 patients receiving aorto-SV bypass grafts to non-left anterior descending targets were identified. To reduce the heterogeneity in the study population, patients receiving concomitant valve or aortic surgery $(n=67)$ and emergency coronary bypass surgery $(n=15)$ were excluded from this study. Patients without MDCT coronary angiogram evaluation were also excluded (hospital death, $\mathrm{n}=6$; renal dysfunction, $\mathrm{n}=21$; refused to undergo computed tomography $[\mathrm{CT}]$ scan, $\mathrm{n}=18$; poor-quality $\mathrm{CT}$ images from arrhythmia, $n=9$; lung atelectasis, $n=8$; or severe obesity, $n=5$ ), resulting in a final number of 309 patients meeting the present inclusion criteria. Of these, individual bypasses only with SV grafts were performed in 212 patients and sequential bypasses only were performed in 78 patients. The remaining 19 patients received both individual and sequential bypass grafts.

The patients were divided into group A (sequential SV bypass grafting) or group B (individual grafting) depending on the bypass grafting technique. The study protocol was reviewed and approved by the Asan Medical Center Institutional Review Board, which waived the need for informed patient consent because of the retrospective nature of this study.

\section{Surgical Techniques and Postoperative Medications}

Surgery was performed via a standard median sternotomy. All SV grafts were harvested by the open technique. Side-to-side anti-parallel anastomoses were performed in single continuous fashion with Prolene 7-0 for the 


$$
\begin{aligned}
& \text { Abbreviations and Acronyms } \\
& \begin{aligned}
\text { CI } & =\text { confidence interval } \\
\text { CT } & =\text { computed tomography } \\
\text { IPTW } & =\text { inverse probability of treatment } \\
& \text { weighting } \\
\text { MDCT }= & \text { multi-detector computed tomography } \\
\text { PI } & =\text { pulsatility index } \\
\text { SV } & =\text { saphenous vein } \\
\text { TTFM } & =\text { transit time flow measurement }
\end{aligned}
\end{aligned}
$$

sequential bypasses. End-to-side anastomoses were performed in single continuous fashion with Prolene 6-0 for the proximal aortic connections and with Prolene 7-0 for the terminal bypasses. The ascending aorta was the proximal inflow for all of the SV bypass grafts, whereas no left internal thoracic artery-SV composite graft was constructed for any patient. In group A, 192 distal targets were sequentially bypassed with 84 SV grafts, and in group B, 244 distal individual targets were bypassed with 244 SV grafts, for a combined total of 436 distal anastomoses with $328 \mathrm{SV}$ graft conduits. In group A, 60 double and 24 triple sequential SV bypass grafts were made. In terms of pump strategy, off-pump coronary bypass surgery was performed in 167 bypasses, on-pump beating heart surgery was performed in 19 bypasses, and conventional surgery under full cardiopulmonary bypass with cardioplegic arrest was performed in 142 bypasses. The selection of cardiopulmonary bypass strategy and bypass grafting technique (ie, offpump coronary bypass surgery vs on-pump, beating vs conventional coronary artery bypass grafting, and individual vs sequential bypassing) were based on surgeon preference and target availability (ie, the number of targets requiring bypasses after left internal thoracic artery to left anterior descending bypass grafting). Statin medication, aspirin, and clopidogrel were routinely prescribed to all of the patients starting from postoperative day 1 or 2. Although statin medication and aspirin were continued indefinitely, clopidogrel was discontinued after 1 year. The dose of statin medication was adjusted for a target low-density lipoprotein level of less than $100 \mathrm{mg} / \mathrm{dL}$.

\section{Transit Time Flow Meter Measurements}

Transit time flow meter (Medistim BF model; Medistim, Oslo, Norway) measurements in the sequential bypass grafts were acquired between the aorta and the first side-to-side anastomosis, whereas in the individual bypass grafts, they were acquired near the proximal aortic anastomosis. Measurements from the proximal site of the sequential bypass graft represented the combined cumulative run-off of the distal anastomosis. The mean flow and pulsatility index (PI) were measured while the heart was beating naturally in the pericardial well independently of any mechanical circulatory support. All flow data were measured under stable conditions of mean systemic pressure greater than $60 \mathrm{~mm} \mathrm{Hg}$ and the heart rate ranging from 60 to 80 beats/min. Protamine was administered after TTFM measurements were deemed appropriate for the circumstances under which the graft flows were measured.

\section{Multi-Detector Computed Tomography Coronary Angiography}

Morphologic assessment of graft patency was made with serial 16-channel MDCT (Somatom Sensation 16, Siemens, Germany) coronary angiograms before November 2006 and with dual-source CT (Somatom Definition, Siemens Medical Solutions, Forchheim, Germany), which is an upgraded version of the 64-channel MDCT, thereafter. Coronary CT angiograms were conducted routinely after coronary bypass surgery unless otherwise contraindicated. Baseline MDCT coronary images were obtained in the early postoperative period before discharge at a mean of $5.70 \pm 1.87$ days postoperatively and a median of 5 (2-14) days. Follow-up imaging studies were subsequently performed 1 and 3 to 5 years thereafter. On the basis of the CT images, grafts were categorized as being patent or poorly patent (graft failure). Nonvisualized or diffusely narrowed grafts with poor stringy visibility were categorized as poorly patent grafts. Poor stringy visualization was represented by luminal enhancement but thread-like narrowing along the entire length of the graft. In the sequential bypass grafts, each anastomotic segment was regarded as a separate bypass graft. Therefore, if a single distal segment of a sequential bypass graft showed nonvisualization, only the anastomoses represented by that segment was regarded as being occluded and the other visualized segments were viewed as being patent. All MDCT results were interpreted and confirmed by experienced radiologists who worked with this modality of coronary imaging on a daily basis.

\section{Statistical Analysis}

Categoric variables were presented as frequencies and percentages, and compared using the chi-square test or Fisher's exact test. Continuous variables were expressed as mean \pm standard deviation or medians with ranges, and were compared using the Student unpaired $t$ test. Kaplan-Meier curves were used to delineate freedom from graft failure, and the Breslow test was used to compare the difference in graft failure-free rates between groups. To reduce the impact of treatment selection bias and potential confounding in an observational study, we performed rigorous adjustment for significant differences in patient characteristics by using inverse probability of treatment weighting (IPTW). With that technique, weights for patients receiving sequential bypassing were the inverse of 1 minus propensity score, and weights for patients receiving individual bypassing were the inverse of propensity score. The propensity scores were estimated by multiple logistic-regression analysis. All prespecified covariates were included in full nonparsimonious models for sequential versus individual bypassing (Table 1). The discrimination and calibration abilities of each propensity score model were assessed by $\mathrm{C}$ statistics and the Hosmer-Lemeshow test. The model was fairly calibrated (Hosmer-Lemeshow test; $P=.126$ ) with reasonable discrimination $(\mathrm{C}$ statistic $=0.741)$. A Cox hazards model was created with IPTW as the weights and treatment effect (sequential or individual bypassing). Results were expressed as hazard ratios with $95 \%$ confidence intervals (CIs). Correlation between the mean flow and PI was evaluated using linear regression. The Kruskal-Wallis method was used to compare mean flow, PI, and the number of distal anastomoses (ie, single SV graft, double sequential SV graft, and triple sequential SV graft).

The predictive value of mean flow and PI for mid-term patency was evaluated using the area under the receiver operating characteristic curves with its $95 \%$ CI. The optimal cutoff corresponded to the value with the greatest accuracy. All reported $P$ values are 2 sided. SAS software, version 9.1 (SAS Institute, Inc, Cary, NC) and SPSS version 12 (SPSS Inc, Chicago, Ill) were used for the statistical analysis.

\section{RESULTS}

Baseline characteristics and patient profiles are summarized in Table 1. The median follow-up duration for the entire cohort was 14.8 months: 11.6 months (1-49 months) for group A and 17.0 months (range, 1-70.2 months) for group B. Coronary imaging studies were performed with 64-channel MDCT in 101 patients and 16-channel MDCT in 208 patients. The mean number of proximal and distal anastomoses with the SV graft per patient was $1.06 \pm 0.24$ and $1.43 \pm$ 0.66 , respectively. For the entire cohort, $407(94 \%)$ graft anastomoses were patent and $29(6.6 \%)$ graft anastomoses were occluded. In group A, 187 (97.4\%) graft anastomoses 
TABLE 1. Preoperative patient profile

\begin{tabular}{|c|c|c|c|c|}
\hline Variable & Group A & Group B & Total & $P$ value \\
\hline No. of grafts & 84 & 244 & 328 & \\
\hline Male, $n(\%)$ & $58(69)$ & $170(69.6)$ & $228(69.5)$ & 1.00 \\
\hline Age, $y$ & $62.9 \pm 8.3$ & $63.7 \pm 8.3$ & $63.5 \pm 8.3$ & .41 \\
\hline Hypertension, n (\%) & $45(53.6)$ & $127(52)$ & $162(49.3)$ & .37 \\
\hline Diabetes mellitus, n (\%) & $48(57.1)$ & $76(31.1)$ & $124(37.8)$ & .001 \\
\hline History of cerebrovascular event, $\mathrm{n}(\%)$ & $13(15.5)$ & $10(4.1)$ & $23(7)$ & .001 \\
\hline Left ventricular ejection fraction, $\%$ & $56.3 \pm 11.0$ & $57.5 \pm 9.6$ & $57.2 \pm 10.0$ & .34 \\
\hline Pump strategy, n (\%) & & & & .001 \\
\hline On pump with ACC & $29(34.5)$ & $138(56.6)$ & $167(50.9)$ & \\
\hline On pump without ACC & 10 (11.9) & $9(3.7)$ & $19(5.7)$ & \\
\hline Off-pump bypass & 45 (54.6) & $97(39.8)$ & $142(43.2)$ & \\
\hline
\end{tabular}

were patent and $5(2.6 \%)$ anastomoses were occluded. In group B, $220(90.2 \%)$ anastomoses were patent and 24 $(9.8 \%)$ anastomoses were occluded. All occlusions in group A involved the terminal end-to-side anastomosis of double sequential bypass grafts, with no occlusions involving triple sequential bypass grafts.

The mean flow was significantly higher in group $\mathrm{A}$ than in group B $(49.4 \pm 27.4 \mathrm{~mL} / \mathrm{min}$ vs $37.1 \pm 20.1 \mathrm{~mL} / \mathrm{min}$, respectively, $P=.001$ ), whereas the PI tended to be lower in group A than in group B $(3.2 \pm 2.2$ vs $4.1 \pm 6.4$, respectively, $P=.24)$. The flow magnitude increased in a linear fashion as the number of anastomoses per graft increased, whereas the PI showing an inverse linear relationship decreased with increasing number of anastomoses (Figure 1). The mean flow plotted against the logarythmic transformation of PI showed a significant inverse relationship on linear regression analysis (Figure 2).

The overall graft patency in group A was significantly superior to that in group B $(P=.048$, Figure 3$)$. Serial patency assessments showed 1-month, 1-year, and 3-year graft patency rates of $96.1 \%, 96.1 \%$, and $93.3 \%$ in group $\mathrm{A}$, respectively, and $97.1 \%, 92.5 \%$, and $86.5 \%$ in group $\mathrm{B}$, respectively. After adjustment for baseline patient characteristics with IPTW, group A showed a tendency toward superior graft patency compared with group B (hazard ratio, 0.362; 95\% CI, 0.129-1.017; $P=.0538$ ).

Evaluation of the relationship between the TTFM measurements and MDCT coronary angiogram data showed higher mean flows in patent compared with poorly patent grafts $(41.3 \pm 22.9 \mathrm{~mL} / \mathrm{min}$ in patent grafts and $29.6 \pm$ $18.7 \mathrm{~mL} / \mathrm{min}$ in poorly patent grafts; $P=.01$ ).

Assessment of the predictive value of mean flow and PI for mid-term graft patency by receiver operating characteristic curve yielded $0.68(95 \% \mathrm{CI}, 0.58-0.78 ; P=.001)$ and $0.61(95 \% \mathrm{CI}, 0.52-0.70 ; P=.044)$ for the area under the curve, respectively. The greatest accuracy for predicting graft patency was obtained at the cutoff value of 24.5 $\mathrm{mL} / \mathrm{min}$ for mean flow $(51.7 \%$ sensitivity and $75.4 \%$ specificity) and 2.15 for PI $(86.2 \%$ sensitivity and $37.6 \%$ specificity).

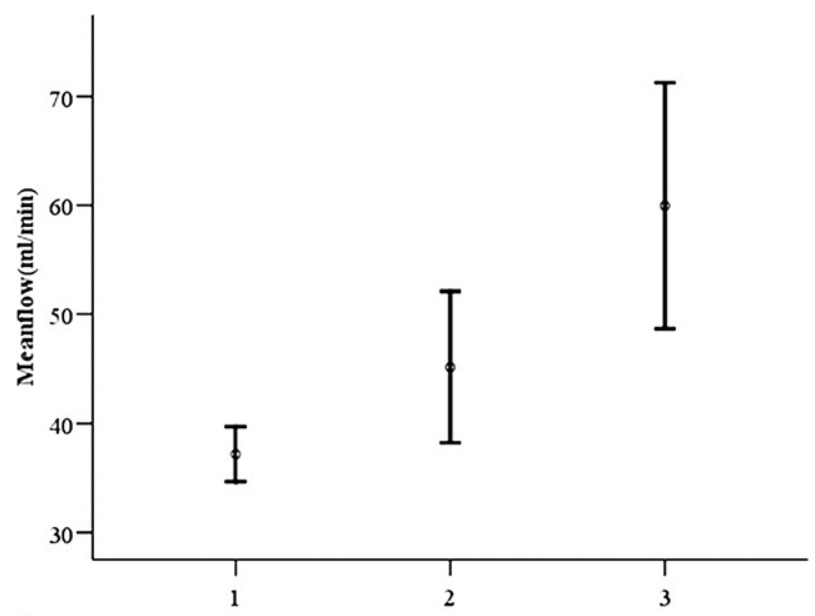

A

Number of Sequential

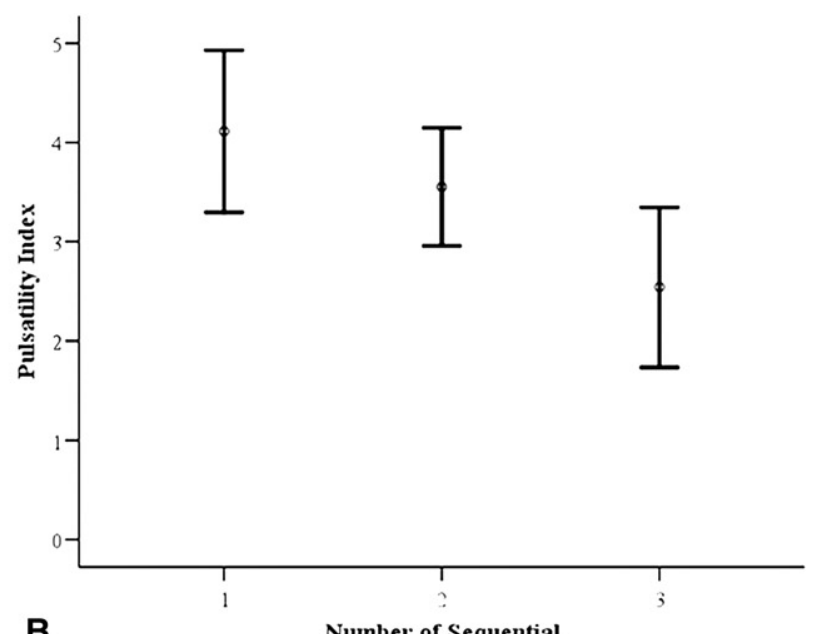

B

Number of Sequential

FIGURE 1. Relationship between hemodynamic flow characteristics and number of distal anastomoses per graft. A, Mean flow versus the number of anastomoses per graft shows a direct linear relationship $(P<.001)$. B. Inverse relationship is shown with the PI $(P=.02)$. Bar represents mean value and $95 \% \mathrm{CI}$. 


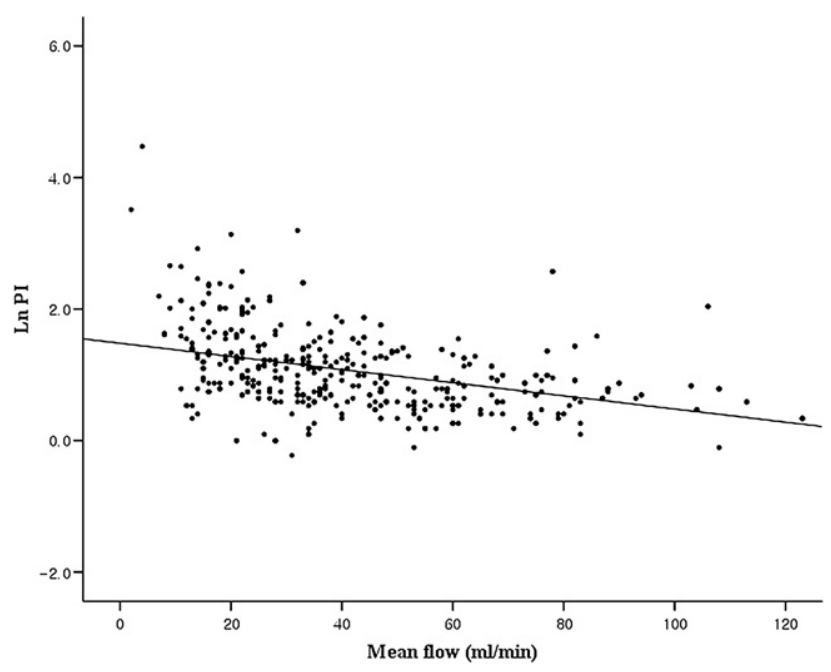

FIGURE 2. Correlation between mean flow and logarithmic transformation of PI values $(L n P I)$. Correlation coefficient $=-0.43, P=001$.

\section{DISCUSSION}

The present study was conducted to investigate the impact of the SV bypass grafting technique on both the intraoperative flow characteristics and the mid-term patency based on previous studies reporting the positive long-term implications of flow characteristics on graft patency. ${ }^{7,8-10}$ The lack of a consensus regarding the optimal bypass grafting technique with the SV graft, despite an inclination for sequential bypass grafting, prompted the present study. We observed the sequential SV bypass grafts to be superior in patency compared with individual grafts.

The favorable effects of intraluminal flow characteristics (ie, mean flow and PI) on both the short- and long-term results reported in previous studies ${ }^{7,8,10}$ agree with basic experimental studies showing the positive influence of flow characteristics in preventing adverse remodeling, neointimal proliferation, and atherosclerotic graft failure. ${ }^{1-6,11-15}$ In chronic canine vascular implant models, flow velocity and wall shear stress correlated inversely with intimal hyperplasia. ${ }^{10,12}$ Wentzel and colleagues ${ }^{13}$ also noted a similar correlation between shear stress and the development of intimal hyperplasia-induced in-stent re-stenosis in human subjects. O'Neill and colleagues ${ }^{6}$ concluded that the flow characteristics of sequential SV grafts were superior to individual grafts on the basis of observations that showed significantly lower vascular resistance and higher flow velocities in the sequential bypass grafts. The significantly greater flows and superior patency of the sequential grafts compared with individual bypass grafts observed in the present study also agree with these results.

Technical difficulties associated with directly measuring arterial vascular resistance have led to indirect methods, such as pulsed-wave Doppler measurements of PI and resistive index (RI). Angiotensin II-induced renal vascular resistance was reported to correlate especially well with PI

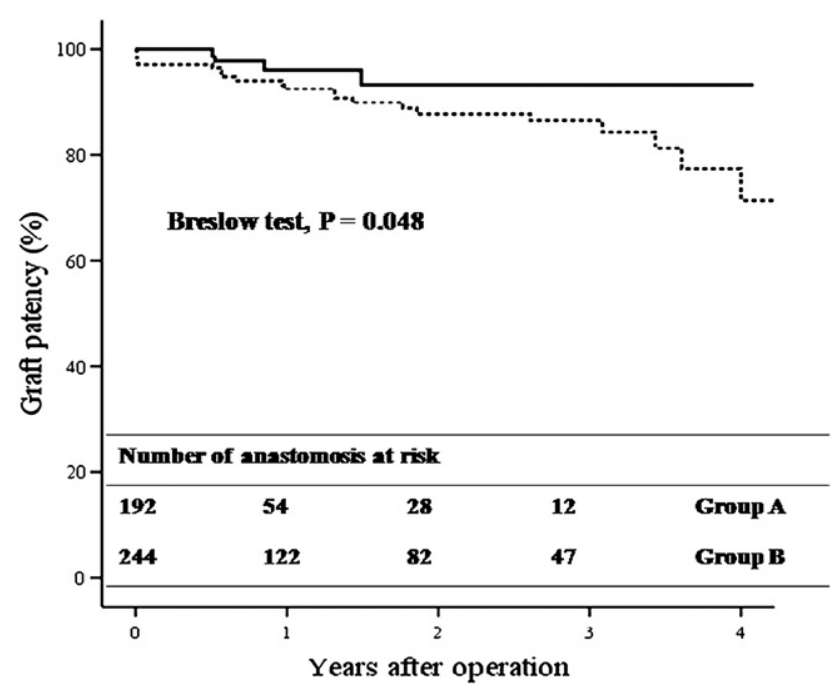

FIGURE 3. Comparison of freedom from graft failure. The solid line represents group A (sequential bypass graft), and the dotted line represents group B (individual bypass graft). Note that group A shows superior freedom from graft failure compared with group B $(P=.048)$.

levels. ${ }^{9,16,17}$ Because the PI, defined as (peak flow-base flow)/(mean flow), indicates reflected flow, ${ }^{18-20}$ increases in overall resistance result in a proportionally larger amount of flow reflection. By using the transit time flow meter, Aleksic and colleagues ${ }^{21}$ showed a close relationship between PI and vascular resistance, and Ofili and associates ${ }^{22}$ described an inverse curvilinear (polynomial) relationship between volumetric flow and vascular resistance in the coronary bed. Consistent with these findings, the flow in the present study increased linearly with an increasing number of anastomoses while the PI decreased in a commensurate manner. The nature of this reciprocal relationship between flow and resistance was further exemplified by the linear regression analyses of the mean flow plotted against the logarythmic transformation of PI (Figures 1 and 2).

Despite the apparent hemodynamic advantages, concerns regarding the potential risk of a high proximal occlusion causing simultaneous myocardial ischemic events in multiple territories have discouraged many surgeons from more actively using the sequential bypass grafting technique. Some surgeons have even advocated a return to the singlegrafting technique. ${ }^{4}$ However, cardiac ischemic events of this nature occurring by this mechanism have rarely been described in the litereature. ${ }^{2,5}$ In the presence of patent distal anastomoses, especially with the terminal coronary bed having the greatest flow reserve, the proximal segment of the sequential bypass graft stands to benefit from the increased cumulative flow. ${ }^{5}$ Should the terminal bypass have a suboptimal runoff, the distal segment would simply behave like an individual bypass graft without causing additional adverse influence on the upstream bypass graft anastomoses. ${ }^{5}$ In the present study, occlusions in the sequential 
bypass grafts were observed in 5 patients, all of which were in the terminal anastomoses. Once past the early postoperative stage, where grafts are most vulnerable to technical failure, further risk of proximal occlusion may be reduced because of the persistence of the favorable hemodynamic flow conditions effected by the sequential grafting technique. ${ }^{9}$

\section{Study Limitations}

The limitations of the present study include those commonly inherent to retrospective observational data analysis. Although the mean flow correlated with mid-term patency, the PI did not show a similar predictive implication. This may be attributed to the small number of occluded grafts, along with the relatively short follow-up period. The use of MDCT instead of selective coronary angiogram, which is currently regarded as the "gold standard" for patency assessment, may also be considered a study limitation. However, the excessive risk of procedure-related complications greatly outweighs the potential benefits of routinely performing coronary angiograms postoperatively, and MDCT has gained a considerable level of acceptance as a reliable diagnostic cardiac imaging modality. For the detection of significant $(\geq 50 \%)$ graft stenosis, 16-channel coronary angiography or MDCT correctly and accurately detected significant stenosis in vein grafts with a sensitivity and specificity of $100 \%$ and $94 \%$, respectively. ${ }^{23}$

The difference in follow-up duration between the 2 groups was statistically significant $(P<.001)$. This difference is attributable to the relatively earlier institution of individual bypass grafting, resulting in its greater predominance. Sequential bypassing was implemented with greater frequency at a later period.

Although the adjusted analyses showed a definite trend toward favoring sequential bypassing than individual bypassing in terms of graft patency, the results were statistically marginal $(P=.0538)$ because of the paucity of poorly patent grafts $(n=29)$. Therefore, studies with a larger population or longer follow-up duration are warranted to verify the current study results.

\section{CONCLUSIONS}

The association of sequential bypass grafting with both higher mean flow rates and superior graft patency indicated the enhanced hemodynamic flow characteristics of sequential bypass grafts to be an important contributory factor in yielding superior results over individual bypass grafts.

The authors thank Sung-Cheol Yun, PhD, from the Division of Biostatistics, Center for Medical Research and Information, University of Ulsan College of Medicine, for assistance with the statistical analyses.

\section{References}

1. Oz BS, Lyem H, Akay HT. Mid-term angiographic comparison of sequential and individual anastomosis techniques for diagonal artery. J Card Surg. 2006;21: 471-4.

2. Christenson JT, Schmuziger M. Sequential venous bypass grafts: results 10 years later. Ann Thorac Surg. 1997;63:371-6.

3. Vural KM, Sener E, Tasdemir O. Long-term patency of sequential and individual saphenous vein coronary bypass grafts. Eur J Cardiothorac Surg. 2001;19:140-4.

4. Kieser TM, FitzGibbon GM, Keon WJ. Sequential coronary bypass grafts. Longterm follow-up. J Thorac Cardiovasc Surg. 1986;91:767-72.

5. Gwozdziewicz M, Nemec P, Simek M, Hajek R, Troubil M. Sequential bypass grafting on the beating heart: blood flow characteristics. Ann Thorac Surg. 2006;82:620-3.

6. O'Neill MJ Jr, Wolf PD, O'Neill TK, Montesano RM, Waldhausen JA. A rationale for the use of sequential coronary artery bypass grafts. J Thorac Cardiovasc Surg. 1981;81:686-90.

7. Di Giammarco G, Pano M, Cirmeni S, Pelini P, Vitolla G, Di Mauro M. Predictive value of intraoperative transit-time flow measurement for short-term graft patency in coronary surgery. $J$ Thorac Cardiovasc Surg. 2006;132:468-74.

8. Tokuda Y, Song M-H, Oshima H, Usui A, Ueda Y. Predicting midterm coronary artery bypass graft failure by intraoperative transit time flow measurement. Ann Thorac Surg. 2008;86:532-6.

9. Petersen LJ, Petersen JR, Ladefoged SD, Mehlsen J, Jensen HA. The pulsatility index and the resistive index in renal arteries in patients with hypertension and chronic renal failure. Nephrol Dial Transplant. 1995;10:2060-4.

10. Louagie YAG, Brockmann CE, Jamart J, Schroeder E, Buche M, Eucher PM, et al. Pulsed Doppler intraoperative flow assessment and midterm coronary graft patency. Ann Thorac Surg. 1998;66:1282-8.

11. S M, Ghista DN, Chua LP, Seng TY. Numerical investigation of blood flow in a sequential aorto-coronary bypass graft model. Conf Proc IEEE Eng Med Biol Soc. 2006; 1:875-8.

12. Keynton RS, Evancho MM, Sims RL, Rodway NV, Gobin A, Rittgers SE. Intimal hyperplasia and wall shear in arterial bypass graft distal anastomoses: an in vivo model study. J Biomech Eng. 2001;123:464-73.

13. Wentzel JJ, Krams R, Schuurbiers JC, Oomen JA, Kloet J, van DGWJ, et al. Relationship between neointimal thickness and shear stress after Wallstent implantation in human coronary arteries. Circulation. 2001;103:1740-5.

14. Rittgers SE, Karayannacos PE, Guy JF, Nerem RM, Shaw GM, Hostetler JR, et al. Velocity distribution and intimal proliferation in autologous vein grafts in dogs. Circ Res. 1978;42:792-801.

15. Faulkner SL, Fisher RD, Conkle DM, Page DL, Bender HW. Effect of blood flow rate on subendothelial proliferation in venous autografts used as arterial substitutes. Circulation. 1975;52:I163-72.

16. Gosling RG, Dunbar G, King DH, Newman DL, Side CD, Woodcock JP, et al. The quantitative analysis of occlusive peripheral arterial disease by a nonintrusive ultrasonic technique. Angiology. 1971;22:52-5.

17. Norris CS, Barnes RW. Renal artery flow velocity analysis: a sensitive measure of experimental and clinical renovascular resistance. J Surg Res. 1984;36:230-6.

18. Beldi G, Bosshard A, Hess OM, Althaus U, Walpoth BH. Transit time flow measurement: experimental validation and comparison of three different systems. Ann Thorac Surg. 2000;70:212-7.

19. D'Ancona G, Karamanoukian HL, Ricci M, Bergsland J, Salerno TA. Graft patency verification in coronary artery bypass grafting: principles and clinical applications of transit time flow measurement. Angiology. 2000;51:725-31.

20. Laustsen J, Pedersen EM, Terp K, Steinbrüchel D, Kure HH, Paulsen PK, et al. Validation of a new transit time ultrasound flowmeter in man. Eur J Vasc Endovasc Surg. 1996;12:91-6.

21. Aleksic M, Heckenkamp J, Gawenda M, Brunkwall J. Pulsatility index determination by flowmeter measurement: a new indicator for vascular resistance? Eur Surg Res. 2004;36:345-9.

22. Ofili EO, Kern MJ, St Vrain JA, Donohue TJ, Bach R, Al-Joundi B, et al. Differential characterization of blood flow, velocity, and vascular resistance between proximal and distal normal epicardial human coronary arteries: analysis by intracoronary Doppler spectral flow velocity. Am Heart J. 1995;130:37-46.

23. Salm LP, Bax JJ, Jukema JW, Schuijf JD, Vliegen HW, Lamb HJ, et al. Comprehensive assessment of patients after coronary artery bypass grafting by 16-detector-row computed tomography. Am Heart J. 2005;150:775-81. 